\title{
Measurement of carbon dioxide production in very low birth weight babies
}

\author{
C C Kingdon, F Mitchell, O A F Bodamer, A F Williams
}

\begin{abstract}
Background- $\mathrm{CO}_{2}$ production is most commonly measured by using indirect calorimetry to quantify elimination of $\mathrm{CO}_{2}$ in breath $\left(\mathrm{VCO}_{2}\right)$. An alternative is to measure the rate at which $\mathrm{CO}_{2}$ appears in the body pool $\left(\operatorname{RaCO}_{2}\right)$ by infusing a ${ }^{13} \mathrm{C}$ labelled bicarbonate tracer. $\mathrm{VCO}_{2}$ and $\mathbf{R a C O}_{2}$ generally differ but are related by $c$, a factor that adjusts for the incomplete recovery of infused tracer in the breath. The literature relating to human studies cites a wide range of values for $c$ but the only neonatal study to determine $c$ empirically estimated a mean value of 0.77 . Aim-To estimate fractional recovery rate, $c$, in very low birthweight babies, and assess the feasibility of using the isotopic technique to measure $\mathrm{CO}_{2}$ production during mechanical ventilation.

Method-Eleven spontaneously breathing, continuously fed, very low birthweight infants (median birth weight $1060 \mathrm{~g}$, median gestational age 29 weeks) were studied.

Results-Mean (SD) $\mathrm{VCO}_{2}$ was 9.0 (2.0) $\mathrm{ml} / \mathrm{min}$ (standard temperature and pressure dry, STPD) and mean (SD) $\mathbf{R a C O}_{2}$ was $9.6(2.1) \mathrm{ml} / \mathrm{min}$ (STPD). The mean (SD) value of $c$ was estimated as 0.95 (0.13). The $95 \%$ confidence intervals of the mean were $0.87-1.03$.

Conclusions-The results emphasise the importance of measuring $c$ for a given study population rather than assuming a value based on adult studies. The close approximation of $\mathrm{RaCO}_{2}$ and $\mathrm{VCO}_{2}$ in this group of babies implies that the labelled bicarbonate infusion technique could be used to measure simply $\mathrm{CO}_{2}$ production during mechanical ventilation.
\end{abstract}

(Arch Dis Child Fetal Neonatal Ed 2000;83:F50-F55)

Keywords: carbon dioxide; carbon isotopes; calorimetry; very low birthweight babies

The measurement of $\mathrm{CO}_{2}$ production has important clinical applications in the management of very small babies. If $\mathrm{O}_{2}$ consumption is measured simultaneously, respiratory quotient can be calculated, allowing total energy expenditure and nature of fuel oxidised to be deduced. Potentially this could help in the choice of more appropriate nutritional interventions for infants who show constrained capacity to eliminate $\mathrm{CO}_{2}$ because of lung disease. Measuring $\mathrm{CO}_{2}$ production is especially problematical in ventilated very low birthweight (VLBW) infants. ${ }^{1}$ Conventionally, breath $\mathrm{CO}_{2}$ elimination $\left(\mathrm{VCO}_{2}\right)$ is calculated by measuring gas flow and the $\mathrm{CO}_{2}$ content of inspired and expired breath. This technique, indirect calorimetry, is subject to both technical errors, such as leakage of expired gas, and confounding by changes in minute ventilation. ${ }^{2}$ An alternative approach is measurement of the rate at which $\mathrm{CO}_{2}$ produced by metabolism appears in the body bicarbonate pool $\left(\mathrm{RaCO}_{2}\right.$, rate of appearance). This can be accomplished by measuring the isotopic enrichment (ratio of ${ }^{13} \mathrm{C}$ to ${ }^{12} \mathrm{C}$ ) of $\mathrm{CO}_{2}$ in expired breath while continuously infusing a ${ }^{13} \mathrm{C}$ labelled sodium bicarbonate tracer at a known rate. ${ }^{34}$

Studies of animals and adult humans have consistently shown that $\mathrm{VCO}_{2}$ and $\mathrm{RaCO}_{2}$ differ. ${ }^{4}$ The discrepancy is principally attributable to incomplete recovery of ${ }^{13} \mathrm{C}$ labelled $\mathrm{CO}_{2}$ in breath when there is insufficient time for infused label to equilibrate between body bicarbonate pools. A correction factor (c), given by the quotient of $\mathrm{VCO}_{2}$ and $\mathrm{RaCO}_{2}$, can be used to adjust for the fractional recovery of tracer. $^{6-8}$ The literature cites mean values of $c$ ranging between 0.5 and 1.06 in different patient groups, ${ }^{45}$ and a value of 0.80 is often assumed in studies of substrate oxidation. A single published study of neonates yielded a mean (SD) estimate of $0.77 \quad(0.05)$ but included only three babies weighing $<1500 \mathrm{~g}^{7}$

In view of the potential importance of accurately quantifying $\mathrm{CO}_{2}$ production in VLBW babies and uncertainty about the magnitude of $c$ in this group, we have simultaneously measured $\mathrm{VCO}_{2}$ and $\mathrm{RaCO}_{2}$ in spontaneously breathing babies and demonstrated the feasibility of applying the isotopic technique during mechanical ventilation.

\section{Methods}

PATIENTS

Eleven spontaneously breathing VLBW (birth weight $<1500 \mathrm{~g}$ ) babies were studied. All had clinically indicated venous access and weighed $<1500 \mathrm{~g}$ at the time of the study. Four were breathing ambient oxygen, seven were breathing air. Feeds were either expressed breast milk $(n=8)$ or a standard preterm formula $(n=1)$ administered by hourly intragastric bolus. One infant received total parenteral nutrition, and one both total parenteral nutrition and expressed breast milk. Table 1 summarises clinical details. A single ventilated baby was later studied to address problems of sampling from the endotracheal tube and to examine within patient variation in $\mathrm{RaCO}_{2}$. St George's Healthcare NHS Trust research ethics committee approved the study; informed written consent was obtained from the parents. 
Table 1 Clinical characteristics of the patients studied

\begin{tabular}{lllllll}
\hline Patient no & $\begin{array}{l}\text { Birth } \\
\text { weight }(g)\end{array}$ & $\begin{array}{l}\text { Gestational } \\
\text { age (weeks) }\end{array}$ & $\begin{array}{l}\text { Study } \\
\text { weight (g) }\end{array}$ & $\begin{array}{l}\text { Postnatal } \\
\text { age (days) }\end{array}$ & $\begin{array}{l}\text { Feeding } \\
\text { regimen * }\end{array}$ & $\begin{array}{l}\text { Estimated energy } \\
\text { intaket } \\
\text { (kcal/kg/day) }\end{array}$ \\
\hline 1 & 1118 & 30 & 1047 & 10 & $\mathrm{e}$ & 108 \\
2 & 1150 & 29 & 1133 & 10 & $\mathrm{e}$ & 128 \\
3 & 1201 & 29 & 1330 & 21 & $\mathrm{e}$ & 109 \\
4 & 1379 & 29 & 1458 & 11 & $\mathrm{e}$ & 105 \\
5 & 715 & 27 & 1190 & 33 & $\mathrm{e}$ & 119 \\
6 & 745 & 25 & 1026 & 30 & $\mathrm{e}$ & 114 \\
7 & 850 & 26 & 1352 & 51 & $\mathrm{e}$ & 115 \\
8 & 734 & 27 & 1033 & 38 & $\mathrm{e}$ & 141 \\
9 & 970 & 29 & 888 & 13 & $\mathrm{e}$ & 105 \\
10 & 1099 & 31 & 1195 & 12 & $\mathrm{p}$ & 110 \\
11 & 1060 & 27 & 940 & 4 & $\mathrm{p}+\mathrm{e}$ & 58 \\
Median & 1060 & 29 & 1133 & 13 & & \\
& & & & & &
\end{tabular}

${ }^{\star}$ e, enteral; $p$, parenteral.

†Estimated on the basis that breast milk had $0.67 \mathrm{kcal} / \mathrm{ml}$, preterm formula used had 0.7 $\mathrm{kcal} / \mathrm{ml}$, and the total parenteral nutrition used had $0.4 \mathrm{kcal} / \mathrm{ml}$.

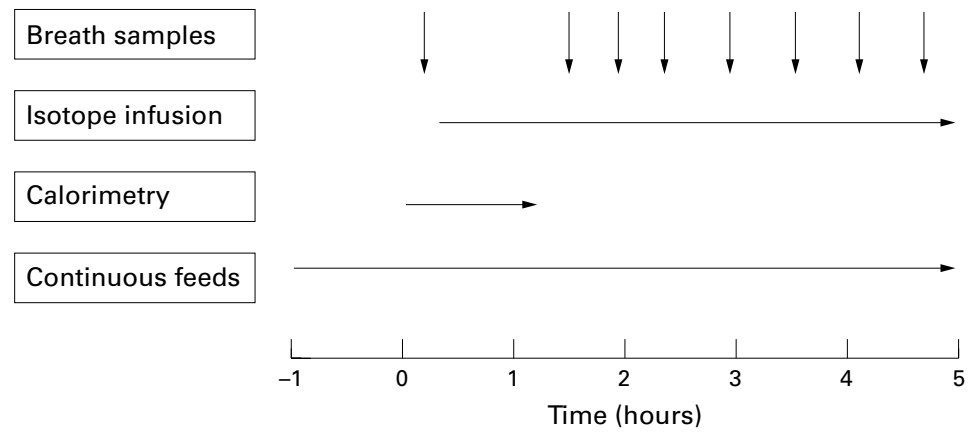

Figure 1 Design of the study.

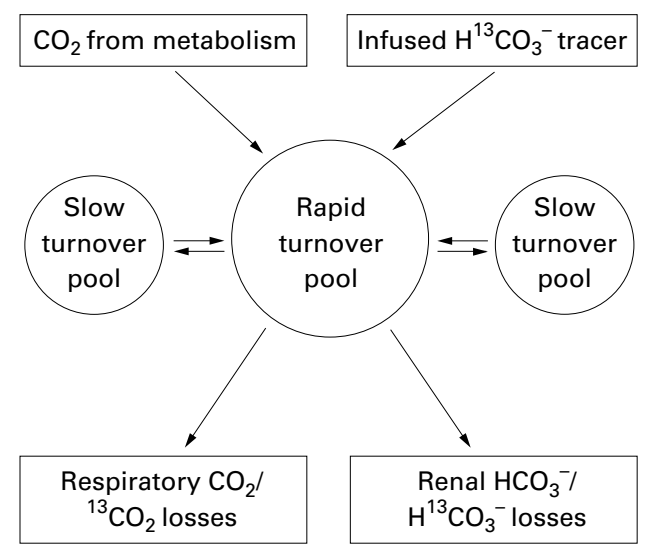

Figure 2 Model of $\mathrm{CO}_{2} / \mathrm{HCO}_{3}^{-}$kinetics. All infused tracer and $\mathrm{HCO}_{3}^{-} / \mathrm{CO}_{2}$ generated by metabolism enters and leaves the body from a central rapid turnover pool. This eventually attains equilibrium with slow turnover pools. The factor $c$ corrects for overestimation of breath ${ }^{13} \mathrm{C} /{ }^{12} \mathrm{C}$ enrichment when a study is too short for this state to be attained.

tope Analysis, Brentford, Essex, UK. (The Bureau provides a postal service at commercial rates.) $\delta$ (del) values were converted into atom percent excess (APE) using the formula ${ }^{8}$ : APE $=[0.0112372 \delta /(0.0112372 \delta+1000)] \times$ 100

The rate of appearance of $\mathrm{CO}_{2}\left(\mathrm{RaCO}_{2}\right)$ was then calculated using the standard single pool model equation ${ }^{6}$ : $\quad \mathrm{RaCO}_{2} \quad(\mu \mathrm{mol} / \mathrm{kg} /$ $\min )=\mathrm{F}\left(\left(\mathrm{E}_{\mathrm{i}} / \mathrm{E}_{\mathrm{b}}\right)-1\right)$

in which $\mathrm{F}$ represents the rate of infusion of $\mathrm{NaH}^{13} \mathrm{CO}_{3}(\mu \mathrm{mol} / \mathrm{kg} / \mathrm{min}), \mathrm{E}_{\mathrm{i}}$ the enrichment of infusate (99\% APE), $\mathrm{E}_{\mathrm{b}}$ the ${ }^{13} \mathrm{C}$ enrichment of expired breath at steady state (in APE). $\mathrm{RaCO}_{2}$ was then converted into $\mathrm{ml} / \mathrm{kg} / \mathrm{min}$, standard temperature and pressure dry (STPD) by applying Avogadro's constant (1 mole of gas $\equiv 22.4$ litres, STPD). Breath isotopic enrichment was plotted against time, and the plateau defined according to the convention of taking four or more consecutive points with a coefficient of variation of $<5 \%$.

MODEL OF $\mathrm{HCO}_{3}{ }^{-}$KINETICS

The single pool model assumes that all bicarbonate administered and $\mathrm{CO}_{2}$ produced by metabolism enters and leaves the body from a single, rapid turnover pool (fig 2). In practice, this probably communicates with slow turnover pools, representing relatively inert tissuesfor example, bone. ${ }^{3}$ During short studies, insufficient time may elapse for tracer equilibration between pools, causing incomplete recovery of tracer in the breath. This will cause overestimation of $\mathrm{RaCO}_{2}$, as breath isotopic enrichment $\left(\mathrm{E}_{\mathrm{b}}\right)$ forms the denominator in the calculation (equation 2). To compensate for this, a correction factor (termed $c$, also known as the fractional recovery rate) can be derived as follows. ${ }^{6-8}$ It is first assumed that all $\mathrm{CO}_{2}$ administered as tracer and produced by metabolism is eliminated only in breath, that body $\mathrm{CO}_{2}$ /bicarbonate pool size is unchanged, and that full equilibration occurs. Under such conditions:

$\mathrm{VCO}_{2}=\mathrm{RaCO}_{2}$

The factor $c$, correcting for incomplete recovery and consequent overestimation of 

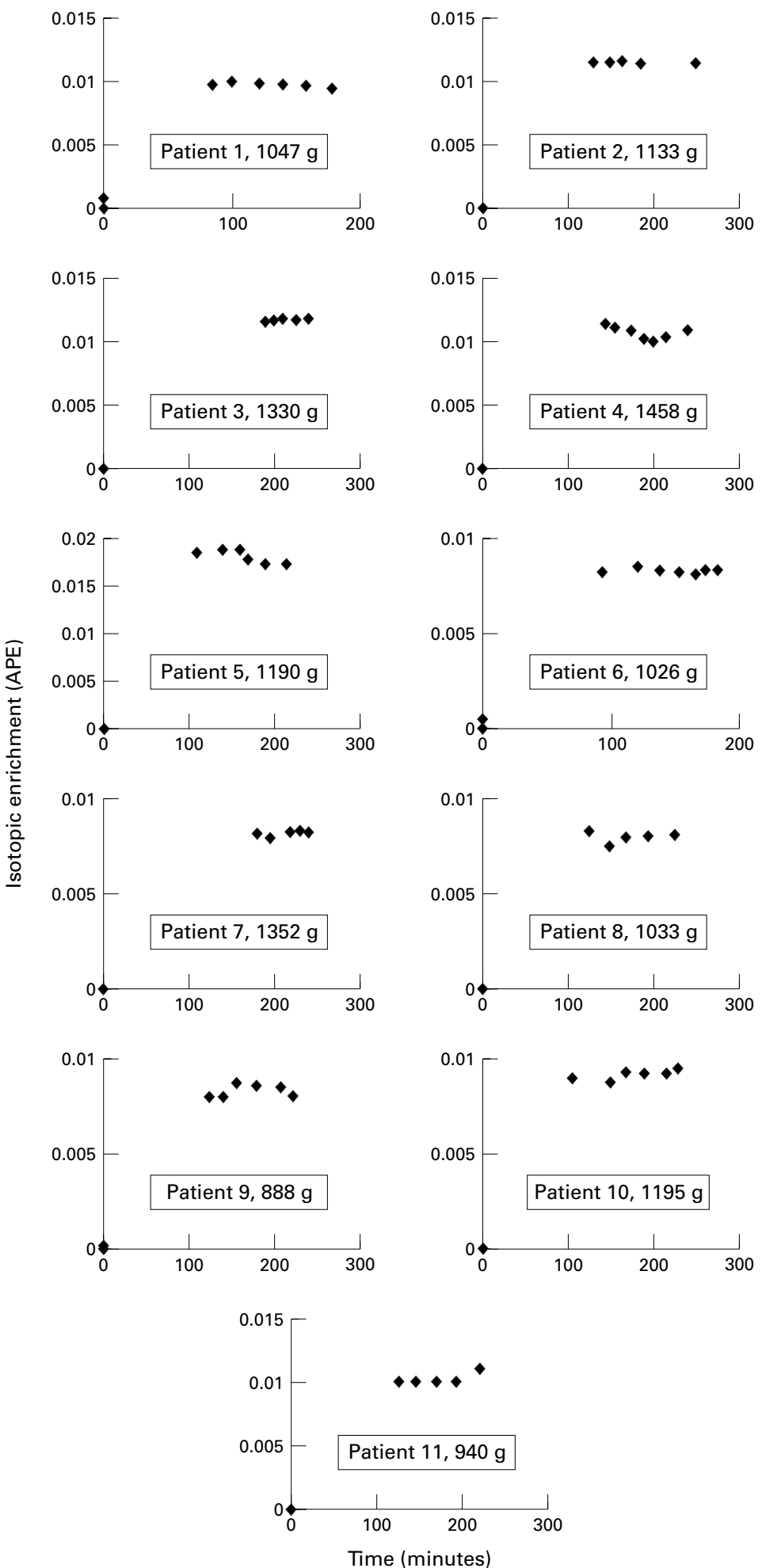

Figure 3 Individual plots of breath enrichment (atom percent excess (APE)) $v$ time. Patient identification numbers correspond to those in tables 1 and 2. Weight at time of study is given.

$\mathrm{RaCO}_{2}$ is then given by:

$\mathrm{VCO}_{2}=c \mathrm{RaCO}_{2}$

which can be rearranged as:

$c=\mathrm{VCO}_{2} / \mathrm{RaCO}_{2}$

MEASUREMENT OF $\mathrm{VCO}_{2}$

Respiratory elimination of $\mathrm{CO}_{2}\left(\mathrm{VCO}_{2}\right)$ was measured using a commercially available open circuit indirect calorimeter (Deltatrac II metabolic monitor). This device offers a choice of four preset canopy flow rates: "baby" (3.1 litres/min), "child" (10.3 litres/min), "adult", and "obese adult". In accordance with manufacturer's recommendations, the instrument was warmed up for at least 30 minutes before two point calibration with room air $\left(\mathrm{CO}_{2}\right.$ content assumed to be $0.04 \%$ ) and Datex calibration gas $\left(4.99 \% \mathrm{CO}_{2}\right.$, later verified by $\mathrm{BOC}$ Analytical Division, Crawley, Sussex, UK). The baby's head and shoulders were placed under the transparent perspex canopy, and a partial seal created by tucking the integral flexible skirt beneath the body and mattress. The child flow range was chosen because Bauer et $a l^{9}$ have concluded that a flow rate of at least 4.5 litres/min is required for accurate measurement of $\mathrm{VCO}_{2}$ using the Deltatrac in canopy mode. We also formally compared child and baby range canopy flow rates by studying four VLBW continuously fed babies over four consecutive one hour periods in a randomised $4 \times$ 4 latin square design (see Results).

ADDITIONAL IN VITRO CALIBRATION OF THE DELTATRAC

The manufacturer recommends that the canopy flow is calibrated by burning alcohol at rates approximating adult $\mathrm{O}_{2}$ consumption and $\mathrm{CO}_{2}$ production. It must then be assumed that canopy flow changes proportionately when the device is switched between baby, child, and adult ranges. We chose in addition to calibrate the instrument directly in child and baby settings by infusing medical grade $\mathrm{CO}_{2}$ (confirmed as $100 \% \mathrm{CO}_{2}$ by BOC Analytical Division) at rates similar to those we encountered clinically.

A mannequin was placed under the canopy to simulate a baby, and $\mathrm{CO}_{2}$ injected at constant rate using a Harvard rotating screw syringe driver with four parallel mounted gas tight $50 \mathrm{ml}$ polypropylene syringes. Connections were made with gas tight three way taps and PVC lines (Datex). Syringes were flushed four times with $\mathrm{CO}_{2}$ to remove air before use. Timed collections of water delivered in the range $4-12 \mathrm{ml} / \mathrm{min}$ showed that $2.777 \mathrm{ml}$ was reproducibly displaced by each revolution of the syringe driver screw. The $\mathrm{CO}_{2}$ injection rate was therefore established by counting rotations of the screw using a vane and slotted optical switch connected to a microcomputer. Gas temperature was measured using an ELAB type CTD thermocouple (ELAB, Copenhagen, Denmark) and volumes corrected to STPD.

\section{Results}

MEASUREMENT OF $\mathrm{RACO}_{2}$

Analysis of variability in background ${ }^{13} \mathrm{C}$ enrichment in the 11 pairs of breath samples collected at baseline of each study showed that there was a small but statistically significant variation between studies (one way analysis of variance, $F=766 ; 10,11 \mathrm{df} ; \mathrm{p}<0.001$ ). This is allowed for in the calculation of APE and $\delta$. Isotopic steady state was achieved in eight subjects by 120 minutes and in all 11 by 200 min- 
Table $2 \mathrm{RaCO}_{2}$ and $\mathrm{VCO}_{2}$ measurements by patient with individual estimates of $c$

\begin{tabular}{llll}
\hline Patient & $\begin{array}{l}\mathrm{RaCO}_{2} \\
(\mathrm{ml} / \mathrm{min} \\
\text { STPD) }\end{array}$ & $\begin{array}{l}\mathrm{VCO}_{2} \\
(\mathrm{ml} / \mathrm{min} \\
\text { STPD })\end{array}$ & $c$ \\
\hline 1 & 7.5 & 8.1 & 1.08 \\
2 & 8.1 & 8.2 & 1.0 \\
3 & 7.5 & 8.9 & 1.19 \\
4 & 10.0 & 9.3 & 0.93 \\
5 & 13.3 & 11.4 & 0.86 \\
6 & 11.1 & 10.3 & 0.93 \\
7 & 12.6 & 13.4 & 1.06 \\
8 & 10.5 & 7.6 & 0.72 \\
9 & 7.5 & 6.5 & 0.87 \\
10 & 9.9 & 8.6 & 0.87 \\
11 & 7.7 & 6.8 & 0.88 \\
Mean & 9.6 & 9.0 & 0.95 \\
SD & 2.1 & 2.0 & 0.13 \\
$95 \%$ CI mean & & & 0.08 \\
\hline
\end{tabular}

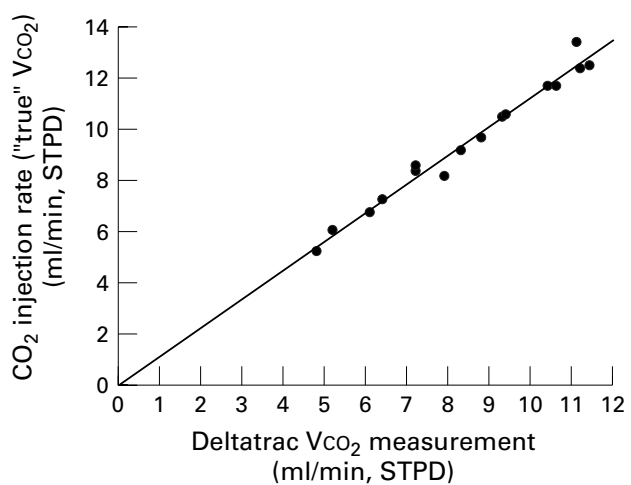

Figure 4 Prediction of true $\mathrm{VCO}_{2}$ from Deltatrac measurement.

utes (fig 3). Mean (SD) $\mathrm{RaCO}_{2}$ was 9.6 (2.1) $\mathrm{ml} / \mathrm{min}$ STPD (table 2), equivalent to 8.5 (1.7) $\mathrm{ml} / \mathrm{kg}$ body weight $/ \mathrm{min}$.

MEASUREMENT OF $\mathrm{VCO}_{2}$

In vitro calibration showed that the Deltatrac consistently underestimated true $\mathrm{CO}_{2}$ injection rates (fig 4), showing greatest discrepancy at highest rates. The relation between $\mathrm{CO}_{2}$ injection rate (y) and simultaneous Deltatrac measurement $(x)$ using the child canopy flow setting was given by $\mathrm{y}=1.12 \mathrm{x}(\mathrm{n}=16$, $r=0.99$; SD residuals $=0.36)$. As there was no intercept term (a), the regression coefficient (slope, $\mathrm{b}=1.12$ ) was subsequently used to correct values of $\mathrm{VCO}_{2}$ measured in vivo. A similar calibration constant was obtained in the baby flow range $(\mathrm{y}=1.13 \mathrm{x}(\mathrm{n}=15, \mathrm{r}=0.99$; $\mathrm{SD}$ residuals $=0.16)$ )

Within patient measurements of $\mathrm{VCO}_{2}$ made using the baby and child flow rates were not significantly different (baby range median 7.4 $\mathrm{ml} / \mathrm{min}$; child range median $7.9 \mathrm{ml} / \mathrm{min}$; $\mathrm{p}=0.7$, Kruskal-Wallis; four babies $\times$ four one hour studies).

Mean (SD) $\mathrm{VCO}_{2}$ measured with the Deltatrac in the 11 babies studied was $9.0(2.0)$ $\mathrm{ml} / \mathrm{min}$, equivalent to 7.9 (1.3) $\mathrm{ml} / \mathrm{kg}$ body weight $/ \mathrm{min}$. $\mathrm{RaCO}_{2}$ exceeded $\mathrm{VCO}_{2}$ in seven.

DERIVATION OF FRACTIONAL RECOVERY RATE, $C$ Mean (SD) $c$ was $0.95(0.13)$. The $95 \%$ confidence intervals of the mean (0.87 to 1.03) included unity. No statistically significant correlation between $c$ and body weight, energy intake, or $\mathrm{VCO}_{2}$ was apparent.

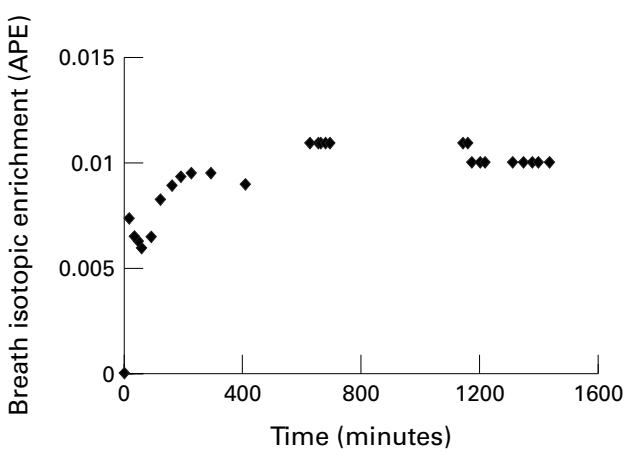

Figure 5 Study of ventilated $658 \mathrm{~g}$ infant. Plot of breath enrichment (atom percent excess (APE)) against time. See text for estimates of $\mathrm{RaCO}_{2}$.

STUDY OF A VENTILATED BABY

To assess the feasibility of measuring $\mathrm{RaCO}_{2}$ in small ventilated babies, we studied a 20 day old $658 \mathrm{~g}$ infant with chronic lung disease (gestational age 25 weeks, birth weight $587 \mathrm{~g}$ ). We and others ${ }^{2}$ have found it impossible to measure $\mathrm{VCO}_{2}$ using the Deltatrac in such circumstances. She was continuously fed with human milk through a nasogastric tube and ventilated with a Babylog 8000 plus ventilator (Dräger, Hemel Hempstead, Herts, UK) at constant pressure, rate, and inspired time settings throughout the 24 hour study period. $\mathrm{FIO}_{2}$ varied between 0.4 and 0.7 , and $\mathrm{PCO}_{2}$ between 5.0 and $6.5 \mathrm{kPa}$. A primed continuous intravenous infusion of $\mathrm{NaH}^{13} \mathrm{CO}_{3}$ was administered at a constant rate for 24 hours using doses given above (see Methods). Breath samples were collected using a syringe connected to a side port (designed for surfactant administration) on the endotracheal tube connector. Figure 5 shows the results. $\operatorname{RaCO}_{2}$ (STPD) was measured over three periods: plateau 1 (260410 minutes, $\mathrm{n}=4, \mathrm{RaCO}_{2}=5.5 \mathrm{ml} / \mathrm{min}$ ); plateau $2\left(630-695\right.$ minutes, $\mathrm{n}=5, \mathrm{RaCO}_{2}=4.9$ $\mathrm{ml} / \mathrm{min}$ ); plateau 3 (1175-1348 minutes, $\left.\mathrm{n}=5, \mathrm{RaCO}_{2}=5.4 \mathrm{ml} / \mathrm{min}\right)$.

\section{Discussion}

Arterial $\mathrm{PCO}_{2}$ reflects a balance between the rate at which $\mathrm{CO}_{2}$ is eliminated through the lungs and the rate at which it is produced by metabolism. Much attention in neonatal intensive care has been focused on controlling elimination by mechanical ventilation, but less has been paid to minimising $\mathrm{CO}_{2}$ production by varying the amount and type of dietary fuel supplied. ${ }^{1}$ Inherent difficulties in measuring the rate of $\mathrm{CO}_{2}$ production in small ventilated babies $^{2}$ may be one reason why nutritional interventions have been largely overlooked. We have shown that the labelled bicarbonate infusion technique can be used to measure simply the rate of $\mathrm{CO}_{2}$ production in VLBW babies, whether spontaneously breathing or mechanically ventilated. We found moreover that estimates of $\mathrm{VCO}_{2}$ and $\mathrm{RaCO}_{2}$ in this group are comparable even in a short term study lasting two to four hours. In this respect, VLBW infants differ significantly from older children and adults.

Our estimate of fractional recovery rate, $c$, in this sample of babies was 0.95 , with $95 \%$ confidence intervals 0.73 to 1.2 including unity. 
This is substantially higher than values previously reported in short term studies. Consideration of the model would suggest that this reflects rapid equilibration of infused isotope between body pools, with minimal trapping in slow turnover pools such as bone. ${ }^{3}$ This seems physiologically plausible, as VLBW babies have a low bone and fat mass, high extracellular fluid volume, and high resting metabolic expenditure relative to older infants. The only other neonatal study we have identified ${ }^{7}$ estimated the mean value for $c$ as 0.77 but recruited more mature babies (mean birth weight 2120 g, mean study weight $2100 \mathrm{~g}$ ), only three of whom weighed $<1500$ g. Estimates in older children and adults have varied from 0.5 to $1.06,{ }^{45}$ although a value of 0.8 is commonly assumed in substrate oxidation studies. In a comparative study, ${ }^{10} \mathrm{RaCO}_{2}$ was found to be much faster in children than in adults, which might further support our hypothesis.

The derivation of equation 4 requires an assumption that $\mathrm{CO}_{2}$ is eliminated only through the lungs. This may be questionable, particularly in immature babies. In adults, about $1 \%$ of $\mathrm{CO}_{2}$ is lost across the skin ${ }^{4}$ and less than $5 \%$ is excreted in the urine, although the exact amount is dependent on urine $\mathrm{pH}^{3}{ }^{3}$ Although we have found no estimates of skin $\mathrm{CO}_{2}$ loss in VLBW infants, a study ${ }^{11}$ of infants weighing $<1000 \mathrm{~g}$ (gestational age 23-29 weeks) confirmed that cumulative bicarbonate loss over the first four days of life was only 1.9 $(0.5) \mathrm{mmol} / \mathrm{kg}$ (mean (SD)). This is equivalent to an equimolar non-respiratory loss of $7.4 \mu \mathrm{l}$ $\mathrm{CO}_{2} / \mathrm{min} / \mathrm{kg}$ body weight. These errors can therefore be considered insignificant.

A further potential source of error in the measurement of $\mathrm{RaCO}_{2}$ is fluctuating background ${ }^{13} \mathrm{C}$ enrichment during the course of a study. Control studies have been undertaken in which subjects underwent the experimental protocol without bicarbonate administration. Most, however, have regarded this as an extremely small potential error and assumed that the initial background enrichment does not change. ${ }^{4}$

Some consider indirect calorimetry the ideal method for measuring $\mathrm{CO}_{2}$ production, but substantial errors can arise when studying small babies. ${ }^{2}$ Our in vitro experiment indicated that particular care is required to calibrate the Deltatrac for use with small infants. Other preliminary experiments (see Results) showed no significant difference between values obtained in vivo using baby and child settings. We took great care to simulate the in vivo situation when calibrating the Deltatrac, to the extent that we used physiologically appropriate rates of $\mathrm{CO}_{2}$ injection, validated the purity of gas used, and placed a baby sized mannequin within the canopy and flexible skirt. If calibration had not been performed, a considerable underestimate of $\mathrm{VCO}_{2}$ would have been made.

As we have shown, potential errors of different sorts apply to the measurement of both $\mathrm{RaCO}_{2}$ and $\mathrm{VCO}_{2}$. This is not surprising, as they measure different aspects of $\mathrm{CO}_{2}$ metabolism. One $\left(\mathrm{VCO}_{2}\right)$ measures the elimination of $\mathrm{CO}_{2}$; the other $\left(\mathrm{RaCO}_{2}\right)$ measures the turnover (or flux, Q) of bicarbonate within the body pool. In steady state, the latter is equivalent to both the rate of appearance ( $\mathrm{Ra}$ ) and rate of disappearance (Rd). Measurement of arterial blood gas status at the beginning and end of each study may have helped to confirm that the bicarbonate $/ \mathrm{CO}_{2}$ pool was in steady state during each study, but we did not feel blood sampling ethically justifiable. Participants showed stable cardiorespiratory measurements throughout and most were breathing air. Moreover the satisfactory enrichment plateaux (fig 3) observed in the 11 studies themselves constitute evidence that the bicarbonate pool was in steady state.

The 11 studies we describe were conducted only for two to four hours, and we have not implied measurements to be representative of longer periods. In deriving $c$, we have made comparisons only between quantities simultaneously measured in the same baby. We performed only one 24 hour study, principally to assess the feasibility of applying the technique in a ventilated baby (fig 5). Although we attempted to measure $\mathrm{VCO}_{2}$ by connecting the Deltatrac monitor to the expiratory port of the ventilator (Dräger Babylog 8000 plus), we obtained no satisfactory measurements, probably because a blow off mechanism in the ventilator allows inspiratory and expiratory gases to mix under certain circumstances. The many problems associated with the measurement of $\mathrm{VCO}_{2}$ during mechanical ventilation have been well described previously. In contrast, measurement of $\mathrm{RaCO}_{2}$ was easily accomplished using the labelled bicarbonate technique and yielded comparable values at the three plateau periods studied.

In summary, we have shown that the labelled bicarbonate infusion technique is easily applicable to the measurement of $\mathrm{CO}_{2}$ production in VLBW babies. In contrast with experience with older children and adults, the adjustment required for retention of infused isotope in short term studies is negligible in this group of patients. This confirms the value of determining the fractional recovery rate, $c$, for individual patient groups. The simplicity of this technique offers new opportunities to study the interaction between fuel metabolism and respiratory function even in the smallest ventilated babies.

We acknowledge the collaboration of Professor David Halliday who undertook breath analyses at the Bureau of Stable Isotope who undertook breath analyses at the Bureau of Stable Isotope
Analysis, Brentford. The study was funded by the St George's Analysis, Brentford. The study was funded
Hospital Special Trustees Research Fund.

1 Forsyth JS, Crighton A. Low birthweight infants and parenteral nutrition immediately after birth. I. Energy expenditure and respiratory quotient of ventilated and non-ventilated infants. Arch Dis Child 1995;73:F4-7.

2 Shortland GJ, Fleming PJ, Walter JH. Validation of a portable indirect calorimetry system for measurement of energy expenditure in sick preterm infants. Arch Dis Child 1992;67:1207-11

3 Elia M, Fuller N, Murgatroyd P. The potential use of the labelled bicarbonate method for estimating energy expenditure in man. Proc Nutr Soc 1988;47:247-58.

4 Leijssen DPC, Elia $\mathrm{M}$. Recovery of ${ }^{13} \mathrm{CO}_{2}$ and ${ }^{14} \mathrm{CO}_{2}$ in human bicarbonate studies: a critical review with original data. Clin Sci (Colch) 1996;91:665-77.

5 El-Khoury AE, Sanchez M, Fukagawa NK, Gleason RE, Young VR. Similar 24-h pattern and rate of carbon dioxide production, by indirect calorimetry vs. stable isotope diluproduction, by indirect calorimetry $v s$. stable isotope dilu-
tion, in healthy adults under standardized metabolic tion, in healthy adults under standar 
6 Kien CL. Isotopic dilution of $\mathrm{CO}_{2}$ as an estimate of $\mathrm{CO}_{2}$ production during substrate oxidation studies. $\mathrm{Am}$ production during subs

7 Van Aerde JEE, Sauer PJJ, Pencharz PB, et al. The effect of energy intake and expenditure on the recovery of ${ }^{13} \mathrm{CO}_{2}$ in the parenterally fed neonate during a 4-hour primed constant infusion of $\mathrm{NaH}^{13} \mathrm{CO}_{3}$. Pediatr Res 1985;19:806-10.
8 Wolfe RR. Radioactive and stable isotope tracers in biomedicine. New York: Wiley-Liss, 1992.

9 Bauer K, Pasel K, Uhrig C, Sperling P, Versmold H. Comparison of face mask, head hood, and canopy for breath sampling in flow-through indirect calorimetry to measure oxygen consumption and carbon dioxide production of preterm infants < 1500 grams. Pediatr Res 1997;41:13944.

10 Armon Y, Cooper DM, Springer C, et al. Oral $\left[{ }^{13} \mathrm{C}\right]$ bicarbonate measurement of $\mathrm{CO}_{2}$ stores and dynamics in children and adults. $\mathcal{F}$ Appl Physiol 1990;69:1754-60.

11 Ramiro-Tolentino SB, Markarian K, Kleinman LI. Renal bicarbonate excretion in extremely low birth weight infants. Pediatrics 1996;98:256-61. 